\title{
Canadian students develop mediwiki to share classroom notes with the world
}

I n 2006, Dr. David LaPierre, then a medical student at Dalhousie University in Halifax, Nova Scotia, wanted a central repository for his notes. Since he was lugging his laptop to class anyway, he figured putting them on a website made sense.

And though his original motivation was to enhance his education, LaPierre thought his website could also help students across Canada and in other countries, especially those in resource-poor areas. And so "Sharing in Health," an open-access resource with many contributors, was born (www.sharinginhealth.ca).

"In the back of my mind, I thought students around the world could benefit from this," says LaPierre, now completing a family medicine residency at the University of Western Ontario in London, Ontario. "I worked on it on my own for a few years, and then asked my classmates at Dalhousie if they would be interested in writing articles and asked professors to review them."

Eventually, LaPierre reached out to students across Canada to participate, not only those in medical programs, but also people studying to become nurses, dietitians and other types of health care professionals. There are now around 100 contributors, mostly from Canada but also from other countries. Their goal is to increase global training capacity, especially in places where learning resources are limited.

"It's growing and growing. In any given week, three to five topics are being put up," says LaPierre. "The target audience is very much primary care workers. All told, the site will probably top out at around 2800 to 3000 topics."
Sharing in Health uses a wiki model, and anyone can apply to be an author, even undergraduates. There is a stringent review process, however, and reviewers

"I have a passion for scientific writing and reading," Kiggundu, an intern at Mulago Hospital in Kampala, Uganda, writes in an email. "Dave [LaPierre] gave me a laptop to use and that's how I started contributing articles and getting other Ugandan students involved.'

In 2010, Kiggundu joined Sharing in Health's board of advisors. He continues to contribute articles, on topics such as ectopic pregnancy and pediatric neurologic examination, and to raise awareness among medical students about how to use and contribute to the website. "Sharing in Health is making it easy for students in health care to freely access information that is updated to supplement their class work," writes Kiggundu, adding that it provides students, especially those in resource-limited settings, access to medical information that is current and well researched.

What's next?

LaPierre would like to introduce case-based learning,

are chosen carefully to ensure they have the requisite skills and right intentions. "There are people out there who have agendas and we don't want them involved with this," says LaPierre.

Only authorized reviewers can log onto the website and make changes to specific topics. And LaPierre, the site's senior editor, gives all articles a "good once over" before they are uploaded for public viewing. In the website's early days, he spent up to 50 hours per week on the initiative. Now, that's closer to 10 hours, and he works mostly to coordinate the efforts of writers and reviewers, as well as to find volunteers. One of those volunteers is Dr. Reuben Kiggundu, whom LaPierre met during a trip to Uganda. with articles adapted for various settings. He also wants to implement an ongoing review process, to ensure all content is reviewed at least once a year and updated with missing material or new findings. The long-term goal is to become a nongovernmental organization (NGO).

"The plan is to become an NGO. I committed very early on never to make any profit from this. I only want to get information into the hands of students," says LaPierre. "Becoming an NGO would allow us to apply for grants. Right now, we are just a group of passionate people without a formal structure." — Roger Collier, CMAJ

CMAJ 2011. DOI:10.1503/cmaj.109-3842 